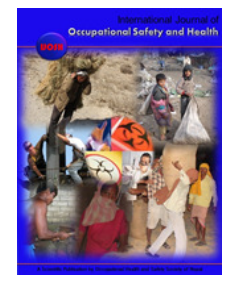

Available Online at http://nepjol.info/index.php/IJOSH

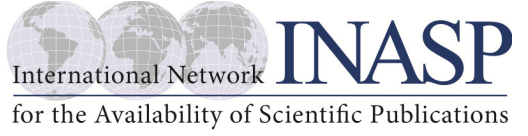

International Journal of Occupational Safety and Health, Vol 2. No 2 (2012) 8 - 13

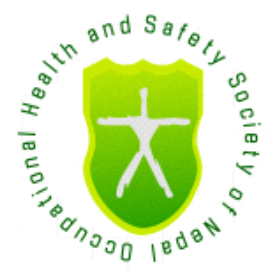

\title{
Assessment of cardiac strain in small - scale aluminium casting works
}

\author{
Rajib Biswas', Alok Ghosh Chaudhuri', Atis Kumar Chattopadhyay ${ }^{3}$, Amalendu Samanta ${ }^{4}$ \\ 'Department of Physiology, Himachal Dental College, Himachal Pradesh \\ ${ }^{2}$ Department of Physiology, Vidyasagar College, Kolkata, West Bengal \\ ${ }^{3}$ Jadaupur University, Kolkata, West Bengal \\ ${ }^{4}$ Foundation for Occupational Health Reform and Developmental Research, Kolkata, West Bengal
}

\section{Abstract:}

The occupational health status scenario in unorganized sector is not impressive. There is a lack of awareness on occupational health and safety issues and manual labour is still obligatory. Ergonomic and work physiological studies conducted among different unorganized sector occupations are scanty.

The present study intended a physiological evaluation of workload in small scale aluminium casting works. In accordance, cardiac strain of the workers is assessed in actual work situation.

Seventeen regular male workers (mean age $32.6 \pm 10.9$; range 22 - 55) years, were examined for the magnitude of physiological strain. Different tasks performed were identified including work and rest hours. Working heart rate, net cardiac cost, relative cardiac cost and recovery heart rates were determined. Tasks performed were analysed in terms of heaviness, recommended strain level and thermal stress of the workplace.

Work study revealed the predominant static nature of the tasks performed. Overall strain of the job appeared to be moderate in nature with mean working heart rate of $99 \pm 5.2$ beats $/$ min. Recovery patterns were inadequate for majority of the workers. Thermal stress prevailing was more than the recommended level.

The subjects were exposed to cumulative circulatory stress which might have deleterious long term effect particularly on older workers. Interventions are required to ameliorate ergonomic stressors, which indicate further scope of study.

Key Words: Aluminium casting, Cardiac strain, Working heart rate, Heat stress

\section{Introduction}

With the advent of globalization, the industrial scenario of the developing countries has witnessed the shift of traditional manual labor-oriented jobs towards more mechanization and automation. With this, there has been a radical change in the occupational morbidity

Corresponding Author: Dr. Rajib Biswas

Email: ergoraj@rediffmail.com

๑) 2012 IJOSH All rights reserved. pattern. The organized sectors in both industrial and nonindustrial settings have witnessed an increasing awareness about occupational safety and health and have adopted health and safety policies. Unfortunately the scenario of unorganized sector is not that impressive; in majority of this sector, manual labour is still obligatory. Lack of awareness about occupational health and safety issues among the workers coupled with their dismal socioeconomic - cultural and nutritional status often make them susceptible to myriads of occupational diseases. 
The present work is a field study. This is exploratory in nature with occupational health research approach. It intends to report the work strain involved in small scale aluminium - casting work that represents one of the informal sectors. In accordance, the specific objective being physiological evaluation of work load in terms of heart rate and certain other cardiac strain indices in relation to thermal stress. The study also aims at physiological characterization of the work methods as well.

\section{Methods}

\section{Subjects}

A total of 22 subjects were selected from 5 different small scale aluminium casting workshops of Kolkata, in eastern India. The workshops were matched for their total number of workers, daily production, worker's salary, size of the working area and work methods. The tasks performed by the subjects in different workshops were similar in nature and performed manually. All workshops were located in ground floor. Two criteria were used for subject selection: full time involvement in the profession with a minimum work experience of 5 years and no current diagnosed illness.

Prior to the study, the subjects were explained about the design of the study and the extent of their involvement. Except three subjects all showed their willingness to comply with the protocol of the study another two subjects were unavailable during field study.

\section{Description of tasks}

The job involved the production of machine parts of various shape and size by aluminium casting. For the purpose, first a mould box was prepared that consists of a upper and lower half.

During this process, the box was layered with casting sand (petrabond) or charcoal dust for lubricating and thermal buffering. Only fine sands were used for the purpose; to ensure all sand lumps were broken, the sand were finely sieved prior to each cast box preparation. In the next step aluminium ingots were melted in furnace at 650 degree centigrade; a bellow was used to increase the temperature. The molten metal was then poured with a ladle in the casting box through sprues. The metal gradually solidifies to produce the cast of desired shape. After the solidification, the box was opened, the cast was replaced and the charcoal dusts were dispersed. The sprues were removed with hacksaw and the casting was given a finishing touch by drilling, saw filling and polishing.
The various tasks that were associated with this operation include preparation of the casting box (CB), dusting and filtering the casting sand (CS), handling the aluminium bars $(A B)$, furnace operation including heating and cleaning (FO), and product finishing (PF).

\section{Description of work place}

The workshops were known as "Bhatti" in local parlance. Each represented a small room with an opening in the front. The dimensions of different workshops varied between 11-15 ft in length, $9-11 \mathrm{ft}$ in breadth and a height of $11 \mathrm{ft}$. All the workshops were roofed with corrugated tin. There were no windows inside for ventilation. At one corner of the room a part of the floor (2 - $3 \mathrm{ft}$ in diameter) was dug and surrounded by furnace bricks that were used as a furnace for melting aluminium ingots.

\section{Field investigation}

Each subject was examined on a single working day. Studies were conducted in the morning between 9.00-17.00 hrs. It was ensured that all the subjects were regularly involved in their job for at least one week before the study.

Working heart rate (WHR) was measured during steady state of work by obtaining the time of 10 inter-beat intervals of radial pulses using an electronic stopwatch.[1,2] Recovery Heart Rate (RHR) was measured in a sitting posture. This was obtained by counting the pulse during the last 30 seconds of each minute in the first, second and third minute of the recovery period, i.e. from $30 \mathrm{sec}$ to 1 minute after work stops (RHR 1), from 11/2-2 minute (RHR 2) and again from 21/2-3 minute (RHR 3). Index of pulse deceleration (PDI) was calculated as RHR1- RHR3. The following criteria were used for classification of the recovery pattern. [3]

i) $\mathrm{PDI}=10$ beats/min and all recovery heart rates below 90 , then recovery is normal.

ii) PDI <10 beats/min and RHR3 > 90 beats/min, then it is considered as no recovery

Net Cardiac Cost (NCC) and Relative Cardiac Cost (RCC) were used as indicators of the cardiac strain. [4,5] Responses were judged in terms of recommended limits of net cardiac cost and relative cardiac cost, [6] acceptable level of working heart rate and relative aerobic cost, [7] pulse deceleration index [3] and limit of continuous work. [8] 
Biswas R et al / International Journal of Occupational Safety and Health, Vol 2. No 2 (2012) 8 - 13

Different environmental parameters viz., natural wet bulb temperature (NWB) and globe temperature (GT) were measured and Wet Bulb Globe Temperature (WBGT) was worked out as an index of heat stress using the equation applicable for indoor environment [9] as follows: WBGT $=0.7 \times$ NWB $+0.3 \mathrm{GT}$.

Each subject was examined throughout a random habitual work shift whilst he was regularly engaged in his work. During the study, the workers maintained their usual work pattern, work-rest regimen and work pace. No instructions were given to them to control their work method. Measurements were taken as quickly as possible without disturbing the normal work pace of the subjects.

\section{Results}

Physical characteristics of the subjects are presented in table 1. The mean height and weight could be compared with average Indian standard. However, for three subjects BMI was less than $18 \mathrm{~kg} / \mathrm{m} 2$ which is considered as energy deficient state. [10]

Table I Physical Characteristics of the subject

\begin{tabular}{|l|c|c|c|}
\hline \multicolumn{1}{|c|}{ Parameter } & Mean & SD & Range \\
\hline Age (years) & 32.6 & 10.9 & $22-52$ \\
\hline Height (cm) & 157.6 & 5.9 & $149-167$ \\
\hline Weight (kg) & 47.3 & 4.7 & $39-55$ \\
\hline Body Surface Area $\left(\mathbf{m}^{2}\right)$ & 1.42 & 0.7 & $1.31-1.49$ \\
\hline Body Mass Index $\left(\mathrm{kg} / \mathrm{m}^{2}\right)$ & 19.6 & 1.8 & $16-22$ \\
\hline Resting heart rate (beats/min) & 76 & 4.9 & $66-86$ \\
\hline Systolic blood pressure (mm - Hg) & 123 & 12.4 & $106-140$ \\
\hline Diastolic blood pressure (mm- Hg) & 91 & 10.7 & $72-110$ \\
\hline Working Experience (years) & 11 & 5.5 & $5-23$ \\
\hline
\end{tabular}

Quantification of daily workload in terms of major work periods is summarized in table 2.

Table II Duration of major work periods

\begin{tabular}{|lcccc|}
\multicolumn{1}{|c}{ Work period } & Mean & SD & Range & $\begin{array}{c}\text { Percentage of } \\
\text { total work shift }\end{array}$ \\
\hline Total shift (hr) & 8.6 & 0.2 & $8.2-8.9$ & - \\
\hline Total productive period (hr) & 6.8 & 0.3 & $6.2-7.3$ & 79.8 \\
\hline Total rest period (hr) & 1.7 & 0.2 & $1.4-2.1$ & 20.2 \\
\hline Non specific rest pauses (min) & 45 & 5.8 & $32-54$ & 8.7 \\
\hline Specific rest pauses (min) & 59 & $\begin{array}{r}12 . \\
1\end{array}$ & $40-80$ & 11.5 \\
\hline
\end{tabular}

The total duration of work shift ranged between 8 and 9 hrs as obtained in different work days. Productive hours were calculated as the difference between total work shift and rest periods. Non specific periods include pauses, delay times and and time spent in non- specific activities, including gossiping, smoking, toilet etc. Specific rest pauses include time spent for lunch and snacks. The total duration of specific and non specific periods were categorized as periods of rest and work pauses.

The duration of different activities is presented in table 3 . It was observed that a single worker performs two or three tasks throughout the work shift; where the majority of the time was spent in a particular task. Therefore combining the work pattern of all the subjects for different tasks, a wide variability was obtained in the duration of different task which is conspicuous in this table. However the time required for furnace operation was almost similar and accounts for half of the total work shift. This was due to the fact that this was considered as a specialized operation and performed by skilled worker throughout the shift while for other activities the tasks were distributed among the workers.

Table III Duration of different tasks.

\begin{tabular}{|l|c|c|c|}
\hline \multicolumn{1}{|c|}{ Tasks } & $\mathrm{n}$ & Duration $(\mathrm{hr})$ & $\begin{array}{c}\text { \% of total work } \\
\text { period }\end{array}$ \\
\hline Cast box preparation & 9 & $4(1.5-6.1)$ & $48(17-82)$ \\
\hline Sand handling & 11 & $2.7(0.6-6.3)$ & $32(6-73)$ \\
\hline Metal handling & 12 & $1.3(0.5-1.9)$ & $15(6-23)$ \\
\hline Furnace operation & 10 & $4.9(4.8-5.3)$ & $58(57-61)$ \\
\hline Product finishing & 12 & $4.4(1.1-5.5)$ & $51(13-62)$ \\
\hline
\end{tabular}

Values are mean (range)

The summary of cardiac responses for different tasks as well as for all activities is presented in table 4 . The cardiac response for a task was obtained by clustering the responses of the workers who spent maximum time for that particular task in the entire work shift. The average time spend in the different activities is thus also mentioned in the table and expressed as the percentage of the total work shift.

Table IV Cardiac strain in different activities

\begin{tabular}{|c|c|c|c|c|}
\hline Tasks & $\begin{array}{c}\text { Duration } \\
\text { mean (range) } \\
\text { as percentage } \\
\text { of total shift }\end{array}$ & $\begin{array}{l}\text { Working } \\
\text { Heart } \\
\text { Rate } \\
\text { (bpm) }\end{array}$ & $\begin{array}{c}\text { Net Cardiac } \\
\text { Cost } \\
\text { (bpm) }\end{array}$ & $\begin{array}{c}\text { Relative } \\
\text { cardiac } \\
\text { cost (\%) }\end{array}$ \\
\hline $\begin{array}{l}\text { Cast box preparation } \\
(n=8)\end{array}$ & $69(63-82)$ & $89 \pm 3.4$ & $11 \pm 3.4$ & $10 \pm 2.0$ \\
\hline Sand handling $(n=7)$ & $68(64-73)$ & $93 \pm 2.8$ & $17 \pm 1.9$ & $15 \pm 2.0$ \\
\hline Metal handling $(n=6)$ & $20(15-23)$ & $103 \pm 4.6$ & $26 \pm 4.4$ & $23 \pm 3.5$ \\
\hline $\begin{array}{l}\text { Furnace operation } \\
(n=7)\end{array}$ & $58(57-61)$ & $114 \pm 4.6$ & $41 \pm 4.5$ & $38 \pm 4.6$ \\
\hline $\begin{array}{l}\text { Product finishing } \\
(n=7)\end{array}$ & $60(58-62)$ & $100 \pm 3.3$ & $25 \pm 5.7$ & $22 \pm 3.5$ \\
\hline All activities $(n=17)$ & $80(75-84)$ & $99 \pm 5.2$ & $23 \pm 7.0$ & $21 \pm 7.2$ \\
\hline
\end{tabular}


The average heart rate for all activities was 99 beats/ min. Working heart rate for different tasks ranged between 81 and 114 beats/min with a relative cardiac cost between $10 \%$ and $38 \%$ with corresponding net cardiac cost between 11 and 41 beats / min. Responses were lowest in cast making and sand handling and highest for furnace operation.

The physical stress associated with different tasks was also judged in relation to the referred limits of certain cardiac strain indices and percentage of workers exceeding those limits for a particular task is presented in table 5 . It is clear that majority of the workers exceeded the limits during furnace operation; a minor percentage exceeded the limits in metal bar handling and product finishing. Responses were all within limits for all subjects in cast preparation and sand handling task.

Table V Percentage of workers exceeding recommended limits of strain indices.

\begin{tabular}{|c|c|c|c|c|}
\hline \multirow[b]{2}{*}{ Tasks } & \multicolumn{4}{|c|}{ Strain indices and recommended levels } \\
\hline & $\begin{array}{l}\text { Limit of } \\
\text { continuous } \\
\text { work = } \\
\text { (resting pulse } \\
+35 \text { beats) }\end{array}$ & $\begin{array}{c}\text { WHR } \\
>110 \mathrm{bpm}\end{array}$ & $\begin{array}{c}\text { NCC } \\
>30 \text { bpm }\end{array}$ & $\begin{array}{l}\mathrm{RCC} \\
>30 \%\end{array}$ \\
\hline $\begin{array}{l}\text { Cast box preparation } \\
(\mathrm{n}=8)\end{array}$ & - & - & - & - \\
\hline Sand handling $(n=7)$ & - & - & - & - \\
\hline Metal handling $(\mathrm{n}=6)$ & - & 17 & 17 & - \\
\hline $\begin{array}{l}\text { Furnace operation } \\
(\mathrm{n}=7)\end{array}$ & 86 & 86 & 100 & 100 \\
\hline $\begin{array}{l}\text { Product finishing } \\
(\mathrm{n}=7)\end{array}$ & 14 & - & 14 & - \\
\hline
\end{tabular}

The mean of 1st, 2nd and 3rd recovery heart rates were $101.5 \pm$ $12.2,97.8 \pm 14.2$ and $94.3 \pm 13.3$ beats/ min respectively. The mean pulse deceleration Index (PDI) was $-6.6 \pm 4.0$ beats/ min. A total of $65 \%$ of worker showed no recovery pattern.

The mean values of wet bulb temperature and globe temperature obtained across all hourly readings in all work days were $80.4 \pm 4.9^{0} \mathrm{~F}$ (range $69-88.7$ )and $98.3 \pm 4.1 \mathrm{~F}$ (range $88-$ 106.7) respectively. The WBGT was obtained as $85.8 \pm 4.2^{0} \mathrm{~F}$ (range $76.2-93.7$ ).

\section{Discussions}

The present study was exploratory in nature and conducted in real work situation. The main objective was to obtain the integrated physiological reactions of the workers in response to different workplace stressors. In accordance, heart rate was chosen as the principal parameter because it provides an integrated response to energy requirement, thermal stress and postural demand $[11,12,3]$ and also reflect the inter individual differences. [13,14]

Observations on work methods revealed predominant static muscular efforts in different activities which might have influenced the physiological reactions. Majority of the tasks were performed in sitting posture. Twisting and bending of trunk were observed in cast making, metal bar handling and product finishing. Frequent upper arm movement was observed in sand sieving and furnace bellowing.

The heaviness of different tasks of casting work could be judged in accordance with the scale of heaviness based on working heart rate. [15] The mean heart rate for all activities was 92 beats/ min. Thus the overall physical strain appeared to be moderate in nature. The workload on the basis of recovery heart rate pattern in Indian context also entails die casting work could be categorized as 'moderate' in nature. [16] In the context of individual tasks, the heart rate reactions in cast making confirmed the job to be light, while handling of sand, metal bars and product finishing could be classified as moderate intensity tasks. However, the furnace operation appeared to be heavy in accordance with this heart rate scale.

The physical strain of the workers could be compared with other occupations in Indian context. The values of working heart rate and relative cardiac costs of casting workers could be compared with fishermen engaged in different inland fishing activities like net pulling and catch handling [17,18], fishing with special appliances [19,20], and as well as in river fishing [21] . Similar heart rates were obtained in women agriculture workers involved in reaping, binding and threshing activities [22] and confectionary workers involved in sweet making [23]. However, the cardiac strain in this study were lower as compared to the physical strain of 'Bheri" fishermen [24 and underground miners engaged in shoveling, drilling and carrying activities. [25,26,27]

An average relative aerobic strain of $35 \%$ with corresponding heart rate of 110 beats/ min was suggested as the recommended limit of acceptable work load in Indian context for an 8 hour work period. [7] The acceptable level for a mixed dynamic and static work was considered as $41 \%$ of VO2max by Rutenfranz [28] and the same for self-paced sustained physical work of 1-2 hour's duration was suggested as $45 \%$ of VO2max by Evans. [29] In the present study, none of these limits were 


\section{Biswas R et al / International Journal of Occupational Safety and Health, Vol 2. No 2 (2012) 8 - 13}

exceeded. Thus it could be suggested that the workers were within an adequate safety margin. In this study, it was observed that the workers maintained their own work pace and rest regime and it could be expected that this self-chosen work pace represented an intensity which was subjectively optimal for different tasks.

However, the recovery heart rates for majority of the workers were inadequate. The second major factor of concern was the thermal stress of the workplace. A WBGT of $27.5^{\circ} \mathrm{C}-28.5^{\circ} \mathrm{C}$ $\left(81.5-83.3^{\circ} \mathrm{F}\right)$ has been recommended for 'moderate' task with work periods ranging from $100 \%$ to $75 \%$ of total work shift. [30] These values are applicable for acclimatized worker. In the present study the subjects may be considered as acclimatized workers as they have full time involvement in their job with a minimum work experience of 5 years. Moreover, all the subjects were regularly involved in their job for at least one week prior to the study. This had negated any possibility of short time acclimatization that might occur when away from heat for a short period and reduced heat tolerance. Therefore, taking into consideration the work-rest regimen of the workers throughout the shift, it appeared that the mean WBGT of $85.8{ }^{\circ} \mathrm{F}$ was above the recommended range and had imposed a considerable amount of thermal load on the workers.

A previous study has found that in die-casting activity heat stress and exposure duration impose significant effect on human performance [31] which was also reflected in the present study. The inadequate recovery as obtained in the present study, could be attributed to the thermal stress coupled with prevalent static work load as indicated in some earlier findings. [3, 6, 12, 32] Moreover, the slow recovery also pointed to the insufficiency of cardiovascular capacity as reported earlier. [33] It therefore appeared that the subjects were exposed to cumulative circulatory stress, which can be a serious health threat particularly for the older working population. Thus it could be suggested that the furnace operation might not be suitable for workers above 40 years of age.

It appeared that the inadequacy of recovery, static postural efforts and environmental heat load represented risk factors that needed to be considered in the present context. The authors strongly believe that the workers were ignorant about the balance between work ability and job demand which could be attributed to the lack of awareness on health and safety issues. Moreover, the dismal socioeconomic status compelled the workers to be least concerned for their health and working situation. In this context, a community based occupational health and safety awareness program focused on unorganized workers is essential to make workers appreciate their work condition and to improve their health and safety at workplace. Furthermore, the present findings also necessitate ergonomic studies to evaluate musculoskeletal workload of the workers.

It can be concluded that aluminium - casting as observed in the present study involved high degree of static effort and was moderately heavy in nature. Care should be taken to reduce the cumulative effect of heat and ergonomic stressors in order to prevent cumulative fatigue and long term health effect.

To reduce the ergonomic stressors of the work place good house- keeping, furnace shielding, better provision for ventilation, arrangement of work seats and awareness training for the workers can be possible remedial recommendations.

\section{References}

4. Das, S K and Maitra S R. A review of the physical work capacity of Indian workers and its implementation in the field with a viewpoint to promote health, efficiency and productivity of the industries. Ind J Physiol \& Allied Sc 1975, 29 (3): $84-91$

5. Nag, P K and Dutta, P. Cardiorespiratory efficiency in some agricultural works. Appl Ergonomics 1980, 11: 81 - 84

6. Brouha, L. Evaluation of physiological requirements of jobs. In: Physiology in industry. UK: Pergamon press, 1960.

7. Trites, D. G., Robinson, D. G. and Banister, E. W..Cardiovascular and muscular strain during a tree planting season among British - Columbia silviculture workers. Ergonomics 1993, 36: 935-49.

8. Costa, G., Berti, F., and Betta, A. Physiological cost of apple farming activities. Ergonomics, 1989, 20: 281-86

9. Brabant, C., Bédard, S., and Mergler, D. Cardiac strain among women worker in an industrial laundry. Ergonomics 1989, 32: 615-628.

10. Saha, P. N., Datta, S. R., Banerjee, P. K. and Narayane, G.G. An acceptable workload for Indian workers. Ergonomics 1979, 22: 1059 - 1071

11. Grandjean , E. Fitting the task to the man (5th Ed). London: Taylor and Francis, 1988.

12. Hatch, TF. Assessment of Heat Stress. In J. D. Hardy (Ed). Temperature: Its Measurement and Control in Science and Industry. Vol. 3, pt. 3, 307, New York: Reinhold, 1963.

13. Naidu, AN and Rao, NP. Body mass Index: a measure of the nutritional status in Indian population. Eur. J. Clin. Nutr 1994, 48 (Suppl): 131- 140

14. Neilsen, R. and Meyer, J P. Evaluation of metabolism from heart rate in industrial work. Ergonomics 1987, 30: 565572.

15. Vogt, JJ, Libert, JP, Candas, V, Dauli, F and Mairiaux, PH. Heart Rate and spontaneous work cycles during exposure to heat. Ergonomics 1983, 26: 1173- 1185. 
16. Green, M. S., Luz, Y., Jucha, E., Cocos, M. and Rosenberg, $\mathrm{N}$. Factors affecting ambulatory heart rate in industrial workers. Ergonomics 1986, 29: 1017-27.

17. Gertner, A., Israeli, R. and Cassuto, Y. Effects of work and motivation on the heart rate of the chronic heat exposed workers during their regular work shifts. Ergonomics 1984, 27: 135- 40.

18. Åstrand, P. O, and Rodhal, K. Text Book of Work Physiology. New York: Mc Graw Hill, 1986.

19. Samanta, A. Recovery heart rate as a tool for the assessment of work stress. Ind J Physiol \& Allied Sc 1984, 38: 123-28.

20. Biswas, R., Samanta, A. Physiological cost of pond fishing. Ind J Physiol \& Allied Sc 2005a, 59: 58 - 68

21. Biswas, $R$ and Samanta, A. Cardiac strain and energy expenditure in inland fishing. In the proceedings of 17 th $\mathrm{Bi}$ ennial Congress of International Ergonomics Association, 9 - 14th August 2009, . Beijing, China, 149- 155,

22. Biswas, R., Samanta, A. and Chatterjee, S. P.Physiological strain in a traditional inland fishing task of India. Ind $\mathrm{J}$ Physiol \& Allied Sc 2001, 55: 61-167.

23. Biswas, R., Samanta, A. Assessment of Physiological strain in inland fishing activity. Indian Journal of Occup Environ Med 2006, 10: $19-23$

24. Biswas, R., Samanta, A. Work stress in river fishing. In the proceedings of the 3rd International conference of Indian society of ergonomics: Humanizing work and work environment (HWWE), Guawahati, Assam, India, 10th 12th December 2005, 55-59.

25. Ghosh, S., Kar, S. K, Sau, S. K., Banerjee, S. and Dhara, P. Cardiovascular stress of women engaged in different paddy cultivation acivities. Ind J Physiol \& Allied Sc 2003, 57: 7482

26. Biswas, R., Samanta, A. and Saha, P. Cardiac strain of confectionary worker in relation to heat exposure during regular work shift. Ind J Occup and Environ Med 2011, 15: 120 $-126$

27. Biswas, R., Samanta, A. Physiological assessment of work stress in inland fishing task. Asian Journal of Ergonomics 2005 c, $6: 27-39$

28. Saha, R., Dey, N C., Samanta, A and Biswas, R. A comparison of cardiac strain among drillers of two different age groups in underground manual coal mines in India. Journal of Occupational Health 2008 a, 50: $512-520$

29. Saha, R., Dey, N C., Samanta, A and Biswas, R. A comparison of physiological strain of carriers in underground manual coal mines in India. Int J Occup Environ Health 2008 b. $14: 210-217$

30. Saha, R., Dey, N C., Samanta, A and Biswas, R. Evaluation of physiological strain of shovellers in underground coal mines in India. Ergonomics SA 2010; 22: 33-48

31. Rutenfranz, J., IImarinen, J., Klimmer, F. and Kylian, H. Workload and demanded physical performance capacity under different industrial working conditions. In M.Kaneko (Ed). Fitness for the aged, disabled and industrial worker,
International series on Sports Sciences. Vol.20, pp. 217-238. Champaign Illinois: Human Kinetics Books, 1990.

32. Evans, W. J., Winsman, F. R., Pandolf, K. B. and Goldman, R. F. Self-paced hard work comparing men and women. Ergonomics 1980; 7: 613-21.

33. ACGIH, American Conference of Governmental Industrial Hygienists. Threshold limit values for Chemical Substances and Physical Agents and Biological Exposure Indices. In 2000 TLVs and BEls (p. 183) Cincinnati, ACGIH: 2000.

34. Muzammil, M., Khan, A A. and Hasan. F. Effect of noise, heat stress and exposure duration on operators in a die casting operation. Occupational Ergonomics 2007, 7: 233245

35. Fuller, FH., and Smith PE. Evaluation of heat stress in a hot workshop by physiological measurement. Am Ind Hyg Assoc J 1982; 42: 32 - 37

36. Bernard, TE. and Kenny, WL. Rationale for a personal monitor for heat strain. Am Ind Hyg Assoc J 1994, 55: 505 514.

\section{Acknowledgement}

The authors are grateful to the Principal, Vidyasagar College and Director of FOHRDR, for rendering all possible facilities for the successful completion of the study. The authors are thankful to the owners of the workshops for giving necessary permission to conduct the study. The authors also convey their special thanks to all the workers who generously volunteered in the study. 